\title{
Is the Ethanol Wet-bonding Technique a Promising One?
}

\author{
¿Es Prometedora la Técnica de Adhesión Húmeda en Etanol?
}

\begin{abstract}
Mário Honorato da Silva e Souza Júnior*; Railson de Oliveira Ferreira*; Joyce Figueira de Araújo*; Thaís Andrade de Figueiredo Barros*; Esther Marina França Braga* \& Sandro Cordeiro Loretto*
\end{abstract}

SOUZA JÚNIOR, M. H. S.; FERREIRA, R. O.; ARAÚJO, J. F.; BARROS, T. A. F.; BRAGA, E. M. F. \& LORETTO, S. C. IS the ethanol wet-bonding technique a promising one? Int. J. Odontostomat., 9(3):463-468, 2015.

ABSTRACT: The ethanol wet-bonding technique (EWBT) was introduced in an attempt to overcome the problems caused by high hydrophilicity and/or incomplete penetration of most commercially available adhesive systems. This strategy provides better conditions for the inter-diffusion of hydrophobic dentin monomers. Today, there are many EWBT protocols, which yield bonding interfaces with minimal degradation and longer durability compared with commercial hydrophilic adhesive systems. The aim of this review is to discuss in greater detail the EWBT, focused on the following aspects: dentin saturation, hydrophobic primer preparation, inactivation of metalloproteinases (MMPs), dentin biomimetic remineralization and the clinical perspectives of this technique. The present review on the EWBT provides support for a better understanding of the behavior of dentin when exposed to dehydration and hydrophobic monomer interaction. Moreover, additional studies are suggested to investigate the long-term stability of this type of hybrid layer.

KEY WORDS: dentin, dentin-bonding agents, ethanol.

\section{INTRODUCTION}

The wet-bonding concept, introduced by Kanca (1992), increased the strength of resin-dentin bonds, allowing good sealing of dentin and significantly decreasing post-operative pain (Pashley et al., 2011). In this bonding approach, organic solvents such as acetone and ethanol added to the hydrophilic monomers displace the water molecules from the demineralized collagen matrix, which is then in part replaced by these monomers (Kanca; Guimarães et al., 2012).

The presence of water within the collagen network plays some important roles such as preserving the interfibrillar spaces among the exposed collagen fibrils and allowing the diffusion of adhesive monomers, which allows the sealing of restoration interface (Malacarne et al., 2006). However, this process requires the presence of a hydrophilic monomer blend that produces polymers that can absorb $5-12 \%$ water (Malacarne et al.), resulting in plasticization that lowers the adhesive interface mechanical properties, and a $30-40 \%$ decrease in bond strength has been observed after 3-6 months of in vitro aging (Hosaka et al., 2009).
Hydrophobic monomers, when added to the adhesives, can produce polymers that are more resistant over time owing to their increased stiffness and resistance to hydrolysis (Guimarães et al.; Breschi et al., 2008). Thus, the durability of the bonded interface is increased compared with that when hydrophilicrich adhesives are applied (Breschi et al.). However, the diffusion of hydrophobic monomers within demineralized dentin is not simple. Air- or blow-drying dentin after rinsing does not remove enough water to allow for favorable interactions between the hydrophobic monomers and the tissue (Figs. 1 and 2). To replace the residual water in the demineralized dentin matrix prior to using adhesives, specific sequences and concentrations of ethanol solutions must be used (Grégoire et al., 2013).

The ethanol-wet bonding technique (EWBT) was introduced in an attempt to overcome the problems caused by incomplete penetration of most adhesive systems and the high hydrophilicity observed in commercially available adhesive systems. Most of the EWBTs have proposed dentin saturation by increasing

* Federal University of Pará, Belém, Brazil.

** Federal University of Maranhão, São Luís, Brazil. 


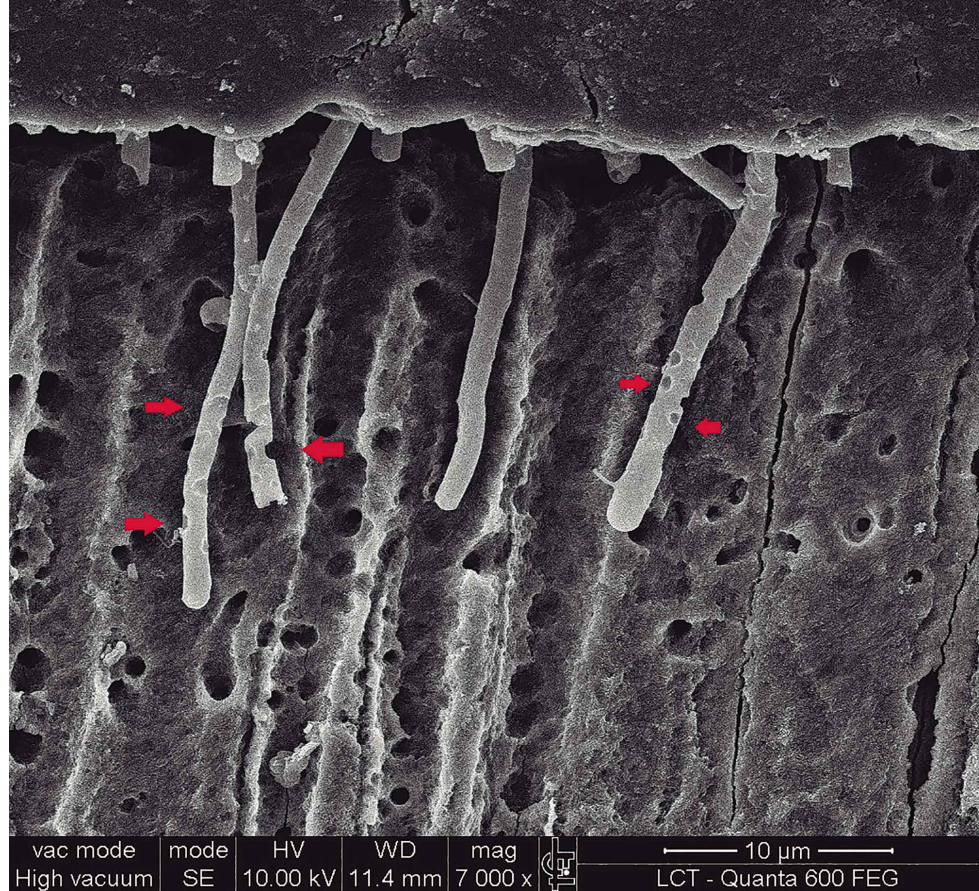

Fig. 1. Poor hydrophilic monomer shows some areas in which the interaction with moist tissue was not achieved (Red arrows).

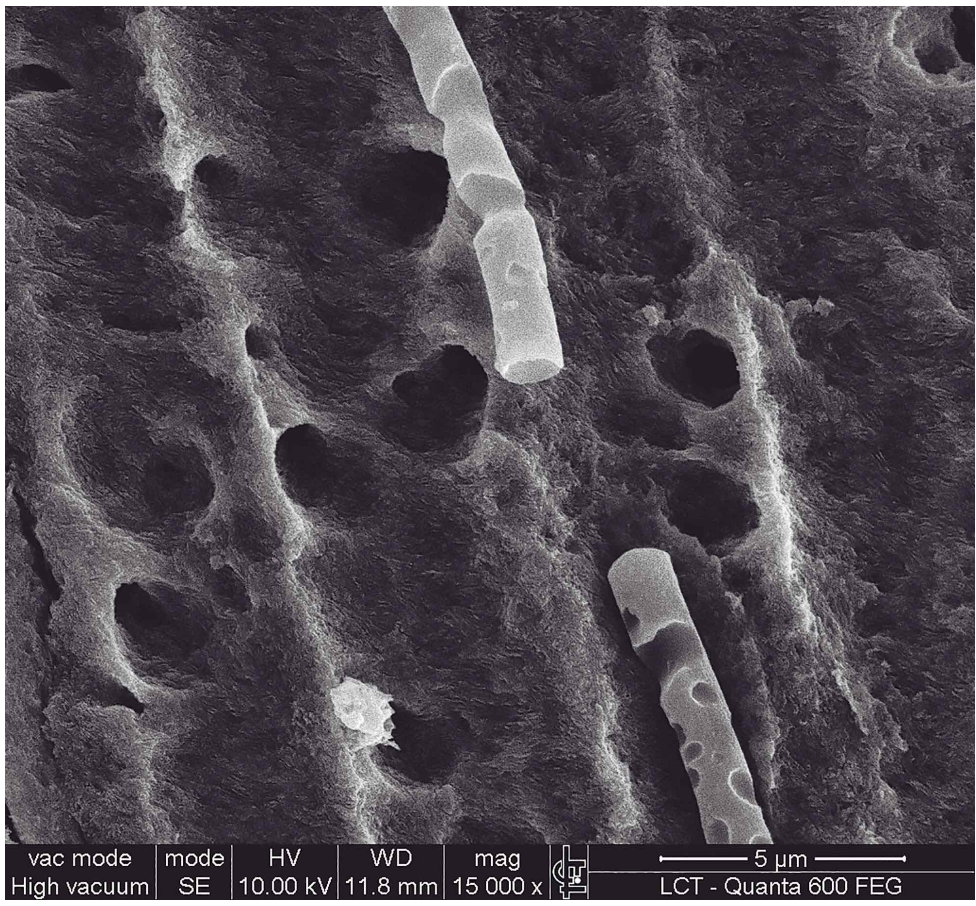

Fig. 2. Closer view of the non-interaction areas between adhesive/moist tissue.

the concentration of ethanol solutions prior to the application of relatively hydrophobic monomers to produce a more stable and hydrolysis-resistant hybrid layer (Pashley et al., 2007; Sadek et al., 2008, 2010a, 2010b). Simpler techniques have also been proposed to reduce the time required to complete the entire procedure, normally by employing one application of $100 \%$ ethanol (Hosaka et al.; Nishitani et al., 2006; Cadenaro et al., 2009; Sadek et al., 2010c).

Another aspect mentioned in the literature is that when ethanol solutions are used to dehydrate etched dentin, collagen fibrils shrink. This shrinkage increases the interfibrillar spaces, which are associated with reduced hydrophilicity of the collagen matrix (Pashley et al., 2011). These conditions may allow the inter-diffusion of higher-molecular-weight molecules present in the hydrophobic monomer formulations; thus, an improved matrix collagen seal may be expected.

Some laboratory studies have demonstrated higher adhesive interface bond strengths when ethanol solutions are used to dehydrate dentin prior to primer and adhesive application compared with the strengths achieved using conventional adhesive techniques (Hosaka et al.; Sadek et al., 2010a, 2010b, 2010c; Nishitani et al.; Cadenaro et al.). Theoretically, hydrophobic resins lead to lower water absorption and smaller plasticization effects, resulting in more durable bonding (Pashley et al., 2011; Malacarne et al.; Breschi et al.; Shin et al., 2009).

Another issue discussed in the literature regarding the EWBT is the primer preparation. Some studies have suggested experimental solutions based primarily on Hoy's solubility parameters to determine the miscibility of the monomers and solvents, as well as the interdiffusion between the monomers and solvent blends and the ethanol-saturated dentin (Hosaka et al.; Sadek et al., 2008, 2010b; Cadenaro et al.). Conversely, there are studies that use commercial bonding systems in which the adhesives were diluted in various concentrations of ethanol (Sauro et al., 2011).

In this article, different dentin saturation protocols and preparations, the use of hydrophobic primers, and the clinical possibilities of the EWBT are discussed in greater detail. 


\section{RESULTS AND DISCUSSION}

Thirty articles were included. This discussion focused on the aspects related to the EWBT, including dentin saturation, hydrophobic primer preparation, inactivation of MMPs, dentin biomimetic remineralization, and the clinical perspectives of the technique.

1. Dentin saturation. The first laboratory techniques that proposed to focus on dentin saturation using the ethanol wet-bonding approach involved the application of increasing concentrations of ethanol (50-100\%) for a duration ranging from $20 \mathrm{~s}$ to $3.5 \mathrm{~min}$ (Hosaka et al.; Sadek et al., 2008; Tay et al., 2007). The full chemical dehydration protocol suggests the application of solutions with increasing concentrations of ethanol as follows: a single 30 -s application of $50 \%, 70 \%, 80 \%$, or $95 \%$, and three applications of a $100 \%$ ethanol solution for $30 \mathrm{~s}$ each. However, this laboratory procedure takes a long time, which makes the technique unattractive and clinically inappropriate. Sadek et al. (2008) showed poor results with one application of $100 \%$ ethanol for $30 \mathrm{~s}$. However, Tay et al. did not observe a difference in the bond strength between the EWBT with one application of a $100 \%$ ethanol solution for $20 \mathrm{~s}$ and the conventional etchand-rinse strategy (Sauro et al.).

Indeed, Nishitani et al., used one application of $100 \%$ ethanol for $20 \mathrm{~s}$ to saturate dentin before using different experimental adhesives diluted in $50 \%$ ethanol and better results in the $\mu$-tensile bond strength tests were observed compared with the results for the same adhesive formulations applied on water-saturated dentin or air-dried dentin. The same protocol with the dentin saturation time increased to $60 \mathrm{~s}$ was used by Hosaka et al. In their study, an increase in the bond strength and durability was observed for the EWBT, and, according to the authors, a higher resin uptake and better resin sealing of the collagen matrix was possible, which may minimize endogenous collagenolytic activity.

2. Hydrophobic primer. To achieve hydrophobic monomer inter-diffusion in the naturally hydrophilic dentin, it is necessary to have previous dentin saturation and hydrophobic monomer dilution with solutions of ethanol. The preparation of ethanol-based hydrophobic primers may vary. Some studies used experimental blends and considered Hoy's solubility parameters to determine the degree of hydrophilicity of the solvated comonomer blends (Nishitani et al.), i.e., to obtain a good affinity between the dentin and monomer blends. The previously mentioned dentin treatment using ethanol solutions and the dilution of monomers in ethanol, results in a favorable interaction between the substrate and primer.

As we noted, there are several different proposals on dentin saturation. Similarly, different methods are reported for monomer solvation. The majority of laboratory studies diluted the monomers in $50 \%$ ethanol (Sadek et al., 2008; Sadek et al., 2010a, 2010c; Cadenaro et al.); however, less diluted solutions have also been proposed (Nishitani et al.). The less concentrated monomer blends show some advantages such as the ability to replace the residual water content within the collagen fiber spaces (Sadek et al., 2008). Conversely, the evaporation of excess ethanol from resin tags composed of more than $30 \%$ ethanol may compromise the interface sealing because of the high residual ethanol content and shrinkage (Pashley et al., 2007; Cadenaro et al.). Dickens \& Cho (2005) stated that it is difficult to evaporate the excess solvent if the ethanol/comonomer blend contains over $30 \%$ solvent. Cadenaro et al. used different monomer blends (hydrophobic $x$ hydrophilic) diluted in $10 \%$ ethanol, and found that the degree of conversion was not affected. Indeed, when the most hydrophobic resin was bonded to ethanol-saturated dentin cured for $60 \mathrm{~s}$, a reduced permeability of $81.2 \%$ was observed. More hydrophilic resins were also used and their permeability when bonded to ethanol-saturated dentin was as high as $92.8 \%$. However, owing to the presence of hydrophilic monomers, higher sorption of water may take place; this plasticizing effect would reduce the stiffness of the resin, resulting in a decrease in bond strength.

The EWBT has been clinically observed in noncarious cervical lesions (NCCL) at 12 months of service compared with a three-step etch-and-rinse system using the commercially available dental adhesive SBMP and the mild self-etching adhesive Adper Easy One (Araujo et al., 2013). For the EWBT, the hydrophobic primer was prepared using SBMP adhesive diluted in $10 \%$ ethanol. The original formulation of the SBMP adhesive is HEMA, Bis-GMA, TEG-DMA, polyalkenoic acid copolymer, and ethanol. This blend is mainly hydrophobic; however, a hydrophilic monomer (HEMA) is present.

One aspect of this procedure must be addressed here: the use of a commercially available product due to ethical considerations. Ideally experimental groups 
would be treated with neat hydrophobic monomer blends diluted in different concentrations of ethanol. However, the use of such experimental solutions in patients could not be justified to the ethics committee (Araujo et al.). Figures 3 and 4 show images taken after the in vitro evaluation of the simplified ethanol technique in an on-going study of our group; a good seal was obtained for dentin coated with the three-step dental adhesive system (SBMP) modified for the EWBT after 18 months of storage in water. It is possible to observe a good interaction after aging between the monomer blend and the tubule demineralized walls.

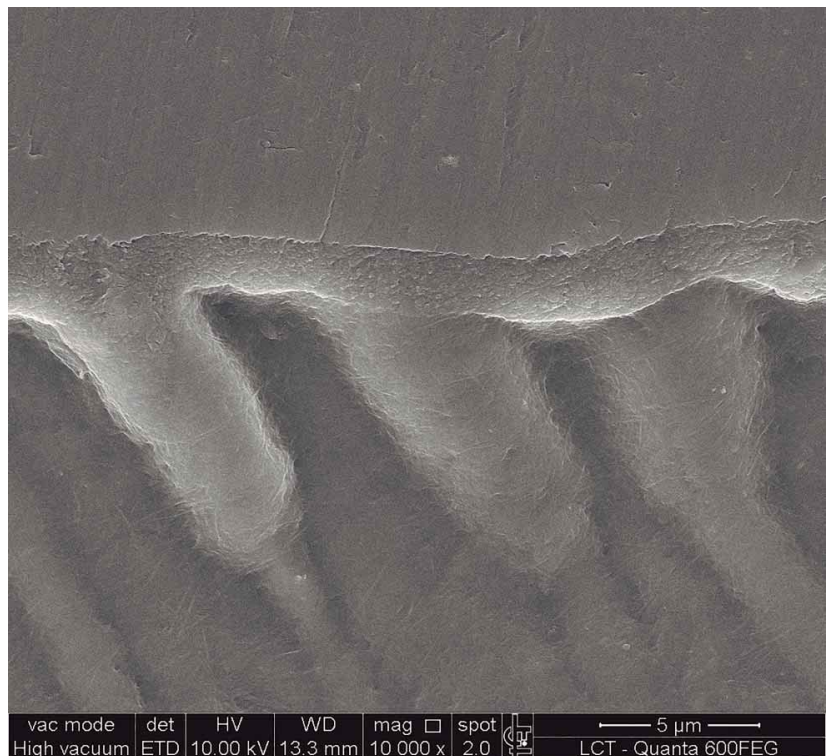

Fig. 3. Non carious lesions restored with the EWBT after 18 months storage. The interface between adhesive system an dentin walls was well preserved.

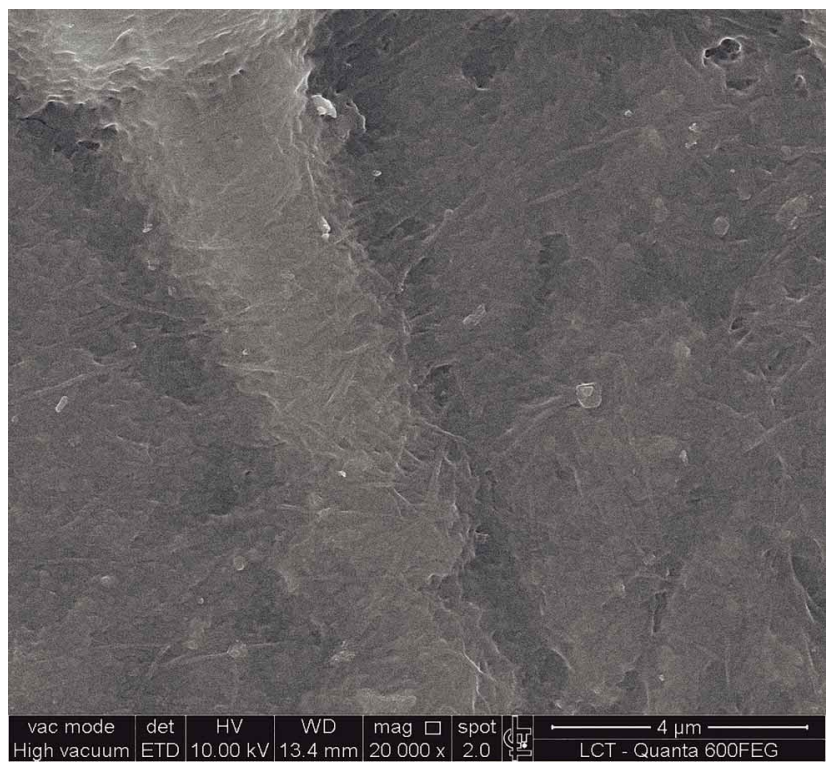

Fig. 4. A closer view of the areas, previously mentioned, showing a good sealing after 18 months.
3. Inactivation of MMPS and biomimetic remineralization of the hybrid layer. The longevity of adhesive interfaces is partially related to the presence of MMPs and their ability to cleave collagen peptide chains (Perdigão et al., 2013). Acid etching activates MMPs and non-infiltrated collagen networks may undergo degradation processes (Pashley et al., 2004). As MMPs become inactive in the absence of water, one may speculate that the replacement of water by an organic solvent such as ethanol might improve the longevity of the bonding interfaces (Perdigão et al.). However, ethanol was not considered as effective as the chlorhexidine (CXD) in inhibiting MMPs (Tezvergil-Mutluay et al., 2010; Liu et al., 2011).

The combination of the EWBT with CXD was evaluated to determine the bond strength after $24 \mathrm{~h}, 9$ months, and 18 months (Sadek et al., 2010c). The reduction of the bond strength in the EWBT with and without CXD was significantly less than that observed for water wet-bonding. It has recently been reported that the EWBT is associated with the possibility of precluding the process of hybrid layer remineralization using biomimetic analogs (Perdigão et al.; Tay \& Pashley, 2009; Niu et al., 2014; Kim et al., 2010). In the present research, changing the moisture condition by replacing water with ethanol showed that the absence of water on the specimens treated with meticulously performed EWBT does not result in the remineralization of the hybrid layer, because water plays a pivotal role in the maintenance of collagen molecules, and consequently, in hybrid layer remineralization (Kim et al.).

However, Kim et al. also showed that the possibility of remineralization can be restricted to watercontaminated ethanol wet-bonded specimens in badly executed EWBT protocols or specimens that were bonded to deep dentin without tubular occlusions (Sadek et al., 2007). Nevertheless, until now the possibility of biomimetic remineralization has only been observed in laboratory trials, and none in clinical situations (Perdigão et al.; Tay \& Pashley; Niu et al.; Kim et al.).

4. clinical perspectives. Although the EWBT seems to bring some long-term benefits, the time needed to replace water with $100 \%$ ethanol within an acid-etched dentin is relatively long and not clinically attractive (Sadek et al., 2010c). Therefore, current adhesive research is directed toward the development of an adhesive that has a good bonding efficiency with enamel and dentin and low technical sensitivity. 
According to this objective, the self-etching adhesives have become the choice of many researchers and practitioners to minimize, the shortcomings between the bonding agents and the dental substrates.

Since last few years, 10-methacryloyloxydecyl dihydrogen phosphate (10-MDP) is being described as a good approach to dental bonding owing to the good outcomes obtained (Pashley et al., 2011; Inoue et al., 2005; Yoshirara et al., 2013; Nikaido et al., 2011). Thus, improved results involving bond strength (Inoue et al.); marginal sealing by chemical interactions between collagen fibrils, hydroxyapatite, and monomers (Inoue et al.; Yoshirara et al.); low nanoleakage; and remineralization of the hybrid layer (Nikaido et al.) have made 10-MDP more commercially attractive to companies developing new products based on this monomer already known as a "gold standard". provides:

In conclusion the present review of the EWBT

1) An improved understanding of the behavior of dentin after undergoing dehydration, e.g., inactivation of
MMPs and preservation of bond integrity;

2) Support for further studies to investigate the longterm stability of the hybrid layer composed of hydrophobic monomers diluted in ethanol for considering the integrity of resin tags, interfacial nanoleakage, remineralization of the hybrid layer "untouched" by the resin monomers, and remineralization of the etched dentin that surrounds the bonding interface.

This review is an important guide to researchers and clinicians searching for long-lasting adhesive interfaces.

\section{ACKNOWLEDGEMENTS}

We would like to thank the Laboratory of Microstructural Characterization (POLI-USP) for the technical support in scanning electron microscopy and CNPQ (Ministry of Science and Technology/Brazil) for the financial support of this study.

SOUZA JÚNIOR, M. H. S.; FERREIRA, R. O.; ARAÚJO, J. F.; BARROS, T. A. F.; BRAGA, E. M. F. \& LORETTO, S. C. ¿Es prometedora la técnica de adhesión húmeda en etanol? Int. J. Odontostomat., 9(3):463-468, 2015.

RESUMEN: La técnica de la adhesión húmeda en etanol (TAHE) se introdujo en un intento de superar los problemas causados por la alta hidrofilicidad y/o la penetración incompleta de la mayoría de los sistemas adhesivos disponibles comercialmente. Esta estrategia ofrece mejores condiciones para la interdifusión de monómeros dentinarios hidrofóbicos. Hoy en día, hay muchos protocolos TAHE que producen las interfaces de unión con mínima degradación y mayor durabilidad en comparación con los sistemas adhesivos hidrofilicos comerciales. El objetivo de esta revisión es discutir con más detalle la TAHE, explicando los siguientes aspectos relacionados: la saturación de la dentina, la preparación del primer hidrofóbico, la inactivación de las metaloproteinasas (MMP's), remineralización biomimética de la dentina, y las perspectivas clínicas de esta técnica. La presente revisión sobre la TAHE proporciona soporte para una mejor comprensión del comportamiento de la dentina cuando es expuesto a la deshidratación y la interacción con monómero hidrófobo. Además, se sugieren estudios adicionales para investigar la estabilidad a largo plazo de este tipo de camada híbrida.

PALABRAS CLAVE: dentina, recubrimientos dentinarios, etanol.

\section{REFERENCES}

Araújo, J. F.; Barros, T. A.; Braga, E. M.; Loretto, S. C.; Silva e Souza, Pde. A. \& Silva e Souza, M. H. One-year evaluation of a simplified ethanol-wet bonding technique: a randomized clinical trial. Braz. Dent. J., 24(3):267-72, 2013.

Breschi, L.; Mazzoni, A.; Ruggeri, A.; Cadenaro, M.; Di Lenarda, R. \& De Stefano Dorigo, E. Dental adhesion review: aging and stability of the bonded interface. Dent. Mater., 24(1):90-101, 2008.

Cadenaro, M.; Breschi, L.; Rueggeberg, F. A.; Agee, K.; Di Lenarda, R.; Carrilho, M.; Tay, F. R. \& Pashley, D. H. Effect of adhesive hydrophilicity and curing time on the permeability of resins bonded to water vs. ethanol-saturated acid-etched dentin. Dent. Mater., 25(1):39-47, 2009.

Dickens, S. H. \& Cho, B. H. Interpretation of bond failure through conversion and residual solvent measurements and Weibull analyses of flexural and microtensile bond strengths of bonding agents. Dent. Mater., 21(4):354-64, 2005.

Grégoire, G.; Sharrock, P.; Delannée, M. \& Delisle, M. B. Depletion of water molecules during ethanol wet-bonding with etch and rinse dental adhesives. Mater. Sci. Eng. C. Mater. Biol. Appl., 33(1):21$7,2013$. 
Guimarães, L. A.; Almeida, J. C.; Wang, L.; D’Alpino, P. H. \& Garcia, F. C. Effectiveness of immediate bonding of etch-and-rinse adhesives to simplified ethanol-saturated dentin. Braz. Oral. Res., 26(2):177-82, 2012.

Hosaka, K.; Nishitani, Y.; Tagami, J.; Yoshiyama, M.; Brackett, W. W.; Agee, K. A.; Tay, F. R. \& Pashley, D. H. Durability of resindentin bonds to water- vs. ethanol-saturated dentin. J. Dent. Res., 88(2):146-51, 2009

Inoue, S.; Koshiro, K.; Yoshida, Y.; De Munck, J.; Nagakane, K.; Suzuki, K.; Sano, H. \& Van Meerbeek, B. Hydrolytic stability of self-etch adhesives bonded to dentin. J. Dent. Res., 84(12):1160-4, 2005.

Kanca, J. 3rd. Improving bond strength through acid etching of dentin and bonding to wet dentin surfaces. J. Am. Dent. Assoc., 123(9):35-43, 1992.

Kim, J.; Gu, L.; Breschi, L.; Tjäderhane, L.; Choi, K. K.; Pashley, D. H. \& Tay, F. R. Implication of ethanol wet-bonding in hybrid layer remineralization. J. Dent. Res., 89(6):575-80, 2010.

Liu, Y.; Tjäderhane, L.; Breschi, L.; Mazzoni, A.; Li, N.; Mao, J.; Pashley, D. H. \& Tay, F. R. Limitations in bonding to dentin and experimental strategies to prevent bond degradation. J. Dent. Res., 90(8):953-68, 2011.

Malacarne, J.; Carvalho, R. M.; de Goes, M. F.; Svizero, N.; Pashley, D. H.; Tay, F. R.; Yiu, C. K. \& Carrilho, M. R. Water sorption/ solubility of dental adhesive resins. Dent. Mater., 22(10):97380, 2006.

Nikaido, T.; Ichikawa, C.; Li, N.; Takagaki, T.; Sadr, A.; Yoshida, Y.; Suzuki, K. \& Tagami, J. Effect of functional monomers in all-inone adhesive systems on formation of enamel/dentin acid-base resistant zone. Dent. Mater. J., 30(5):576-82, 2011.

Nishitani, Y.; Yoshiyama, M.; Donnelly, A. M.; Agee, K. A.; Sword, J.; Tay, F. R. \& Pashley, D. H. Effects of resin hydrophilicity on dentin bond strength. J. Dent. Res., 85(11):1016-21, 2006.

Niu, L. N.; Zhang, W.; Pashley, D. H.; Breschi, L.; Mao, J.; Chen, J. H. \& Tay, F. R. Biomimetic remineralization of dentin. Dent. Mater., 30(1):77-96, 2014.

Pashley, D. H.; Tay, F. R.; Yiu, C.; Hashimoto, M.; Breschi, L.; Carvalho, R. M. \& Ito, S. Collagen degradation by host-derived enzymes during aging. J. Dent. Res., 83(3):216-21, 2004.

Pashley, D. H.; Tay, F. R.; Carvalho, R. M.; Rueggeberg, F. A.; Agee, K. A.; Carrilho, M.; Donnelly, A. \& García-Godoy, F. From dry bonding to water-wet bonding to ethanol-wet bonding. A review of the interactions between dentin matrix and solvated resins using a macromodel of the hybrid layer. Am. J. Dent., 20(1):720, 2007.

Pashley, D. H.; Tay, F. R.; Breschi, L.; Tjäderhane, L.; Carvalho, R. M.; Carrilho, M. \& Tezvergil-Mutluay, A. State of the art etchand-rinse adhesives. Dent. Mater., 27(1):1-16, 2011.

Perdigão, J.; Reis, A. \& Loguercio, A. D. Dentin adhesion and MMPs: a comprehensive review. J. Esthet. Restor. Dent., 25(4):21941, 2013.

Sadek, F. T.; Pashley, D. H.; Ferrari, M. \& Tay, F. R. Tubular occlusion optimizes bonding of hydrophobic resins to dentin. J. Dent. Res., 86(6):524-8, 2007
Sadek, F. T.; Pashley, D. H.; Nishitani, Y.; Carrilho, M. R.; Donnelly, A.; Ferrari, M. \& Tay, F. R. Application of hydrophobic resin adhesives to acid-etched dentin with an alternative wet bonding technique. J. Biomed. Mater. Res. A., 84(1):19-29, 2008.

Sadek, F. T.; Castellan, C. S.; Braga, R. R.; Mai, S.; Tjäderhane, L.; Pashley, D. H. \& Tay, F. R. One-year stability of resin-dentin bonds created with a hydrophobic ethanol-wet bonding technique. Dent. Mater., 26(4):380-6, 2010a.

Sadek, F. T.; Mazzoni, A.; Breschi, L.; Tay, F. R. \& Braga, R. R. Sixmonth evaluation of adhesives interface created by a hydrophobic adhesive to acid-etched ethanol-wet bonded dentine with simplified dehydration protocols. J. Dent., 38(4):276-83, 2010 b.

Sadek, F. T.; Braga, R. R.; Muench, A.; Liu, Y.; Pashley, D. H. \& Tay, F. $R$. Ethanol wet-bonding challenges current anti-degradation strategy. J. Dent. Res., 89(12):1499-504, 2010c.

Sauro, S.; Toledano, M.; Aguilera, F. S.; Mannocci, F.; Pashley, D. H.; Tay, F. R.; Watson, T. F. \& Osorio, R. Resin-dentin bonds to EDTAtreated vs. acid-etched dentin using ethanol wet-bonding. Part II: Effects of mechanical cycling load on microtensile bond strengths. Dent. Mater., 27(6):563-72, 2011.

Shin, T. P.; Yao, X.; Huenergardt, R.; Walker, M. P. \& Wang, Y. Morphological and chemical characterization of bonding hydrophobic adhesive to dentin using ethanol wet bonding technique. Dent. Mater., 25(8):1050-7, 2009.

Tay, F. R.; Pashley, D. H.; Kapur, R. R.; Carrilho, M. R.; Hur. Y. B.; Garrett, L. V. \& Tay, K. C. Bonding BisGMA to dentin--a proof of concept for hydrophobic dentin bonding. J. Dent. Res., 86(11):1034-9, 2007.

Tay, F. R. \& Pashley, D. H. Biomimetic remineralization of resin-bonded acid-etched dentin. J. Dent. Res., 88(8):719-24, 2009.

Tezvergil-Mutluay, A.; Agee, K. A.; Hoshika, T.; Carrilho, M.; Breschi, L.; Tjäderhane, L.; Nishitani, Y.; Carvalho, R. M.; Looney, S.; Tay, F. R. \& Pashley, D. H. The requirement of zinc and calcium ions for functional MMP activity in demineralized dentin matrices. Dent. Mater., 26(11):1059-67, 2010.

Yoshihara, K.; Yoshida, Y.; Nagaoka, N.; Hayakawa, S.; Okihara, T.; De Munck, J.; Maruo, Y.; Nishigawa, G.; Minagi, S.; Osaka, A. \& Van Meerbeek, B. Adhesive interfacial interaction affected by different carbon-chain monomers. Dent. Mater., 29(8):888-97, 2013.

\section{Correspondence to:}

Prof. Dr. Mário Honorato Silva e Souza Júnior

Federal University of Pará

Tv. Humaitá, n.2018, apto. 1703,

Belém, PA

BRAZIL

Email: mario-honorato@hotmail.com

Received: 31-06-2015

Accepted: 08-10-2015 